\title{
Subthalamic Lesion or Levodopa Treatment Rescues Giant GABAergic Currents of PINK1-Deficient Striatum
}

\author{
Nathalie Dehorter, ${ }^{1}$ Natalia Lozovaya, ${ }^{1}$ B. Julius Mdzomba, ${ }^{1}$ François J. Michel,,${ }^{1}$ Catherine Lopez, ${ }^{1}$ Vera Tsintsadze, ${ }^{1}$ \\ Timur Tsintsadze, ${ }^{1}$ Michael Klinkenberg, ${ }^{2}$ Suzanna Gispert, ${ }^{2}$ Georg Auburger, ${ }^{2}$ and Constance Hammond ${ }^{1}$ \\ ${ }^{1}$ Institut de Neurobiologie de la Méditerranée UMR 901, Inserm and Aix Marseille University, 13009 Marseille, France, and 2Experimental Neurology, \\ Department of Neurology, Goethe University Medical School, 60528 Frankfurt am Main, Germany
}

Cellular electrophysiological signatures of Parkinson's disease described in the pharmacological 6-hydroxydopamine (6-0HDA) animal models of Parkinson's disease include spontaneous repetitive giant GABAergic currents in a subpopulation of striatal medium spiny neurons (MSNs), and spontaneous rhythmic bursts of spikes generated by subthalamic nucleus (STN) neurons. We investigated whether similar signatures are present in Pink $1^{-1-}$ mice, a genetic rodent model of the PARK6 variant of Parkinson's disease. Although 9- to 24-month-old Pink $1^{-1-}$ mice show reduced striatal dopamine content and release, and impaired spontaneous locomotion, the relevance of this model to Parkinson's disease has been questioned because mesencephalic dopaminergic neurons do not degenerate during the mouse lifespan. We show that $75 \%$ of the MSNs of 5- to 7-month-old Pink ${ }^{-1-}$ mice exhibit giant GABAergic currents, occurring either singly or in bursts (at $40 \mathrm{~Hz}$ ), rather than the low-frequency $(2 \mathrm{~Hz})$, low-amplitude, tonic GABAergic drive common to wild-type MSNs of the same age. STN neurons from 5- to 7-month-old Pink $1^{-1-}$ mice spontaneously generated bursts of spikes instead of the control tonic drive. Chronic kainic acid lesion of the STN or chronic levodopa treatment reliably suppressed the giant GABAergic currents of MSNs after 1 month and replaced them with the control tonic activity. The similarity between the in vitro resting states of Pink1 MSNs and those of fully dopamine (DA)-depleted MSNs of 6-OHDA-treated mice, together with the beneficial effect of levodopa treatment, strongly suggest that dysfunction of mesencephalic dopaminergic neurons in Pink ${ }^{-1-}$ mice is more severe than expected. The beneficial effect of the STN lesion also suggests that pathological STN activity strongly influences striatal networks in Pink1 ${ }^{-1-}$ mice.

\section{Introduction}

Electrophysiological signatures of Parkinson's disease (PD) described in pharmacological animal models include spontaneous, repetitive giant GABAergic currents occurring in 50\% of striatal medium spiny neurons (MSNs), and spontaneous, rhythmic bursts of spikes generated by glutamatergic neurons of the subthalamic nucleus (STN) (Bergman et al., 1994; Benazzouz et al., 2000; Dehorter et al., 2009). These signatures were recorded after toxic lesion or dopamine depletion of the dopaminergic terminals in the basal ganglia. Here we investigated whether similar signatures are present in the genetic mouse model of the PARK6 variant of Parkinson's disease in which midbrain dopaminergic (mDA) neurons are preserved during the mouse lifespan.

Received May 23, 2012; revised 0ct. 16, 2012; accepted 0ct. 26, 2012.

Author contributions: G.A. and C.H. designed research; N.D., N.L., B.J.M., F.J.M., C.L., V.T., T.T., M.K., and S.G. performed research; N.D. and C.H. analyzed data; G.A. and C.H. wrote the paper.

The study was financed by Inserm, Association France-Parkinson (C.H.), ERA-Net Neuron (C.H.), the Deutsche Forschungsgemeinschaft (GI 432/3-1), and the Bundesministerium für Forschung through the National Genome Research Network (NGFNplus).

The authors declare no competing financial interests.

Correspondence should be addressed to Constance Hammond, UMR 901 Inserm, INMED, 163 route de Luminy, BP 13, 13273 Marseille cédex 9, France. E-mail: constance.hammond@inserm.fr.

N. Dehorter's present address: Instituto de Neurociencias de Alicante CSIC, Universidad Miguel Hernández, 03550 Alicante, España.

B. J. Mdzomba's present address: Bernstein Focus Neurotechnology and Johann-Friedrich-Blumenbach Institute for Zoology and Anthropology, University of Göttingen, D-37075 Göttingen, Germany.

DOI:10.1523/JNEUROSCI.2474-12.2012

Copyright $\odot 2012$ the authors $\quad 0270-6474 / 12 / 3218047-07 \$ 15.00 / 0$
Autosomal recessive PARK6-linked Parkinsonism, an earlyonset variant of Parkinson's disease with slow progression, is caused by loss-of-function mutations in the mitochondrial protein PINK1 (Bentivoglio et al., 2001; Gasser, 2009). PINK1 encodes the PTENinduced putative kinase 1 (PINK1), a ubiquitously expressed 581 aa protein with a mitochondrial localization signal and a cytoplasmic serine-threonine kinase domain (Zhou et al., 2008). In response to cellular stress, PINK1 is transcriptionally induced with Parkin and exerts a neuroprotective function (Mei et al., 2009; Klinkenberg et al., 2012). 123I-FP-CIT-SPECT analysis to determine the amount of presynaptic dopamine transporter in PARK6 patients showed reduced binding, similar to idiopathic PD patients (Kessler et al., 2005).

Pink $1^{-/-}$mice have been generated to determine the mechanisms underlying the PARK6 variant of PD. Pink $1^{-/-}$mice show reduced locomotor activity starting at 16 months (Gispert et al., 2009). Horizontal activity, movement time, stereotypy count, and center distance are decreased by $\sim 30 \%$ in open field, while strength and coordination remain normal. Unlike the neurons of Parkinson's disease patients, mDA neurons of the Pink $1^{-1-}$ do not degenerate during the murine lifespan. However, striatal dopamine is significantly reduced by 9 months of age, evoked striatal dopamine release is reduced and synaptic plasticity in corticostriatal slices is disrupted by 3 months (Kitada et al., 2007; Gispert et al., 2009). These observations show that loss of mDA neurons is not required for disruption of the Pink $1^{-/-}$motor pathway, if dopamine release and its actions are altered. As such, 
this provides a unique model to determine the temporal correspondence between electrophysiological signatures of Parkinson's disease, motor pathology and degeneration of $\mathrm{mDA}$ neurons.

Here, we used a variety of electrophysiological techniques in slices in vitro to determine whether Pink $1^{-1-}$ mice have the expected electrophysiological signatures of dopamine depletion (Bergman et al., 1994; Benazzouz et al., 2000; Dehorter et al., 2009). We report that in slices from Pink1-deficient brains 10 months before the onset of motor deficits, the striatum exhibits the characteristic signs of DA depletion; spontaneous, repetitive, giant GABAergic currents in MSNs and spontaneous, rhythmic bursts of spikes in neurons of the STN. In addition, either unilateral kainic acid lesion of the STN or chronic levodopa treatment can rescue the Pink $1^{-1-}$ striatal pathology.

\section{Materials and Methods}

Slice preparation. Mice from the 129 sv strain of either sex, either wildtype (wt) or Pink1 ${ }^{-1-}$ mutant, were killed at age $5-7$ months by decapitation under halothane anesthesia. Oblique parasagittal slices $(380 \mu \mathrm{m}$ thick) were cut with an angle of $10 \pm 2^{\circ}$ to obtain the basal ganglia slice (BGS) as described previously (Beurrier et al., 2006). For the slicing procedure, the ice-cold oxygenated solution contained (in mM) 110 choline, $2.5 \mathrm{KCl}, 1.25 \mathrm{NaH}_{2} \mathrm{PO}_{4}, 7 \mathrm{MgCl}_{2}, 0.5 \mathrm{CaCl}_{2}, 25 \mathrm{NaHCO}_{3}, 7$ glucose. During the recovery period, BGSs were placed at room temperature with standard artificial CSF (ACSF) saturated with $95 \% \mathrm{O}_{2} / 5 \% \mathrm{CO}_{2}$ and containing (in mM): $126 \mathrm{NaCl}, 3.5 \mathrm{KCl}, 1.2 \mathrm{NaH}_{2} \mathrm{PO}_{4}, 1.3 \mathrm{MgCl}_{2}, 2 \mathrm{CaCl}_{2}, 25$ $\mathrm{NaHCO}_{3}, 11$ glucose.

STN lesion. We unilaterally lesioned the STN in Pink $1^{-1-}$ mice aged 5-7 months by local stereotaxic injection of kainic acid under $5 \%$ ketamine (Imalgène 1000)-2.5\% xylazine (Rompun 2\%) anesthesia (8-10 $\mu \mathrm{l} / \mathrm{g}$, i.p.). The microinjection of kainic acid was performed through a NanoFIL syringe (outside diameter $135 \mu \mathrm{m}$, WPI) placed into the left STN at the following coordinates using a David Kopf stereotaxic apparatus: $0.7 \mathrm{~mm}$ rostral to bregma, $1.48 \mathrm{~mm}$ lateral to the midline, $4.55 \mathrm{~mm}$ below the surface of the skull. Kainic acid was dissolved in saline and injected at a dose of $1 \mathrm{mg} / \mathrm{ml}$ in a volume of $0.3 \mu \mathrm{l}$ over a $3 \mathrm{~min}$ period. The syringe was left in place for $3 \mathrm{~min}$ after the end of injection. We performed in vitro recordings at least $30 \mathrm{~d}$ after the lesion. The efficacy of the STN lesion was determined just after recovery from anesthesia on video film (lying on the left side with the right hindlimb in extension), documented in films of lesion effects (see Notes). We checked the extent of the lesion by counting the number of double-labeled neurons with NeuN (neuronal-specific nuclear protein) and DAPI ( $4^{\prime}, 6^{\prime}$-diamidino2-phenylindole dihydrochloride) in serial $100 \mu \mathrm{m}$ sections of the STN (see Immunocytochemistry).

Levodopa treatment. We treated Pink $1^{-1-}$ mice aged 5-7 months over a $15 \mathrm{~d}$ period with a daily injection of benserazide hydrochloride (DLserine 2-(2,3,4-trihydroxybenzyl)hydrazide hydrochloride, $10 \mathrm{mg} / \mathrm{kg}$, i.p.), a DOPA decarboxylase inhibitor that does not cross the bloodbrain barrier, and $20 \mathrm{~min}$ later a levodopa injection (10 mg/kg, i.p.).

Electrophysiology. All recordings were made at $32^{\circ} \mathrm{C}$. Cells were visualized with infrared-differential interference optics (Axioskop2, Zeiss). For whole-cell voltage-clamp recordings of postsynaptic $\mathrm{GABA}_{\mathrm{A}}$ currents, the pipette (6-10 M $\Omega$ ) contained (in $\mathrm{mM}$ ): 120 Cs-gluconate, $13 \mathrm{CsCl}, 1$ $\mathrm{CaCl}_{2}, 10$ HEPES, 10 EGTA, pH 7.2-7.4, 275-285 mOsm, or (in mM): 128.5 K-gluconate, $11.5 \mathrm{KCl}, 1 \mathrm{CaCl}_{2}, 10$ EGTA, 10 HEPES, $2.5 \mathrm{MgATP}$, and $0.3 \mathrm{NaGTP}, \mathrm{pH}$ 7.32, $280 \mathrm{mOsm}$. The CsGlu and KGlu pipette solutions gave a reversal potential for chloride close to -58 and $-63 \mathrm{mV}$ at $35^{\circ} \mathrm{C}$, respectively. Biocytin (Sigma, $5 \mathrm{mg} / \mathrm{ml}$ ) was added to the pipette solution and osmolarity was corrected when necessary. We performed patch-clamp recordings in whole-cell configuration using the Digidata 1344A interface, the Multiclamp 700A amplifier, and PClamp8 software (Molecular Devices). We identified MSNs during recordings based on their typical rectification during hyperpolarizing steps and their firing delay in response to depolarizing steps. STN neurons were identified during recordings by their position inside the STN. MSNs and STN neurons were also identified by their morphological characteristics after the recording session (see Immunocytochemistry).

We measured spontaneous $\mathrm{GABA}_{\mathrm{A}}$ currents $\left(\mathrm{GABA}_{\mathrm{A}}\right.$ sPSCs) from MSNs in voltage-clamp mode at the reversal potential for glutamatergic $(+10 \mathrm{mV})$ events (Cossart et al., 2000). These currents were stored on Pclamp8 (Molecular Devices) and analyzed off-line with Mini Analysis program (Synaptosoft 6.0), Clampfit 9.2, Origin 5.0, and Autosignal 1.7 to determine the frequency and amplitude of $\mathrm{GABA}_{\mathrm{A}} \mathrm{sPSCs}$. All detected currents were then visually inspected to reject artifactual events. As previously published (Dehorter et al., 2009), we defined as "giant" any single $\mathrm{GABA}_{\mathrm{A}}$ sPSC with an amplitude $>200 \mathrm{pA}$, because such sPSCs were rarely recorded in wt MSNs (on average only nine events per cell; see Results). We defined as a burst a minimum of five sPSCs associated with a baseline elevation. More than five giant events and three bursts were required during the $3 \mathrm{~min}$ analysis for the pattern to be deemed "oscillatory." The current charge was automatically calculated by the Mini Analysis Software as the area under the curve value (taking the onset, peak and decay time points as references for each event). We recorded STN neuron activity in current or voltage-clamp modes, with patch electrodes filled with the K-gluconate solution.

Drugs. Drugs were prepared as concentrated stock solutions and diluted in ACSF for bath application: bicuculline, a $\mathrm{GABA}_{\mathrm{A}}$ receptor antagonist, D-(-)-2-amino-5-phosphonopentanoic acid (D-APV), a NMDA receptor antagonist, 6-cyano-7-nitroquinoxaline-2,3-dione (CNQX), an AMPAkainate receptor antagonist, and kainic acid. All drugs were purchased from Sigma. DL-Serine 2-(2,3,4-trihydroxybenzyl)hydrazide hydrochloride (benserazide) and $\alpha$-methyl-L-tyrosine (levodopa) were purchased from Sigma.

Immunocytochemistry. After the recording session, to visualize and identify the recorded neurons in the striatum and the STN, we visualized the biocytin injected during whole-cell recordings. After $24 \mathrm{~h}$ in paraformaldehyde $(3 \%)$ at $4^{\circ} \mathrm{C}$, the sections were rinsed in PBS and preincubated for $1 \mathrm{~h}$ in $0.3 \%$ Triton X-100 (Abcys) in PBS with 5\% normal goat serum (NGS) at room temperature. Slices were then incubated in Streptavidin-Cy3 (1:500) in PBS-Triton X-100 (0.3\%) and NGS (5\%) during $12 \mathrm{~h}$ at $4^{\circ} \mathrm{C}$. After thorough rinsing, slices were mounted in Fluoromount and coverslipped. Confocal Images were taken with a Leica SP5-X and stacks were filtered (median 3D) and stitched (3D stitching) with FIJI software (ImageJA v1.46b, Open source software, http://pacific.mpi-cbg.de). Dendritic and axonal arbors were reconstructed for morphological analysis using the Neurolucida system (MicroBrightField Inc.). All the measures of dendritic length were corrected in each plane individually with a shrinkage factor to compensate for dehydration and processing of slices (Pyapali et al., 1998). For visualizing the STN lesion we performed NeuN (Neuronal Nuclei) immunocytochemistry (mouse monoclonal antibody, 1:1000, Millipore Bioscience Research Reagents) detected by Cy3 streptavidin (1:1000). Then slices were counterstained with DAPI.

Statistics. For statistical comparison of data we performed nonparametric Mann-Whitney tests unless otherwise stated.

\section{Results}

Spontaneous $\mathrm{GABA}_{\mathrm{A}}$ currents increase in amplitude and shift to oscillatory mode in Pink1 ${ }^{-/-}$MSNs

Seventy percent of the recorded MSNs $(n=7 / 10)$ from 5 - to 7-month-old wt mice displayed a tonic pattern of $\mathrm{GABA}_{\mathrm{A}}$ sPSCs, with low-frequency $(1.7 \pm 0.8 \mathrm{~Hz})$ and low-amplitude events $(32.6 \pm 2.9 \mathrm{pA})$ (Fig. 1A1). The current charge of this tonic pattern averaged $134 \pm 56 \mathrm{nA} . \mathrm{ms}$. In the other $30 \%$ of the recorded MSNs $(n=3 / 10)$ we also recorded rare giant $(>200 \mathrm{pA})$ currents (mean amplitude: $219 \pm 5$ pA; range: $201-246 \mathrm{pA}$, mean frequency: $0.032 \pm 0.004 \mathrm{~Hz} ; n=27$ events 3 cells) (Fig. 1A2). The overall current charge of this pattern was $343 \pm 218$ nA.ms. Because there was no significant difference between the total current charge of the two patterns $(p=0.4)$, these data were pooled $(\mathrm{A} 1+\mathrm{A} 2$, mean current charge $197 \pm 75$ nA.ms, Fig. $1 C)$.

In 5- to 7-month-old Pink1 ${ }^{-1-}$ MSNs $(n=27)$ a new pattern emerged, characterized by a much higher total current charge 


\section{A wt GABAA SPSCs}

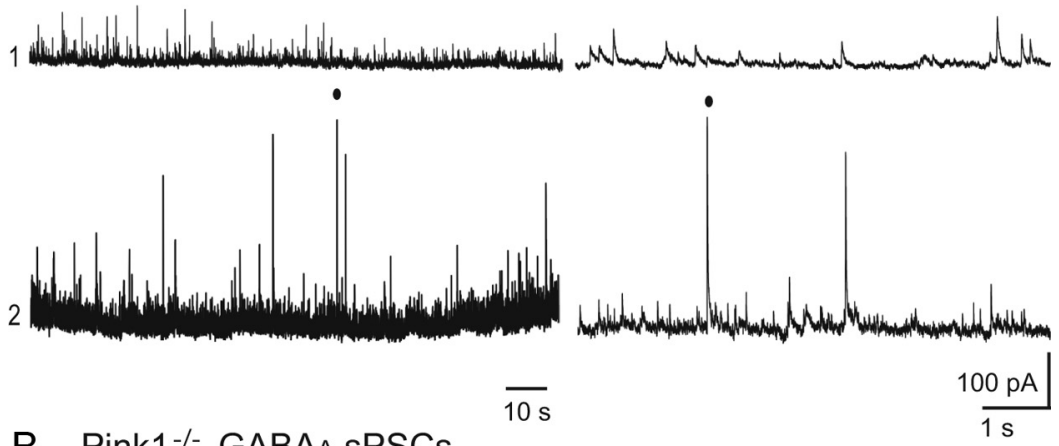

B Pink $1 \%$ GABAA sPSCs
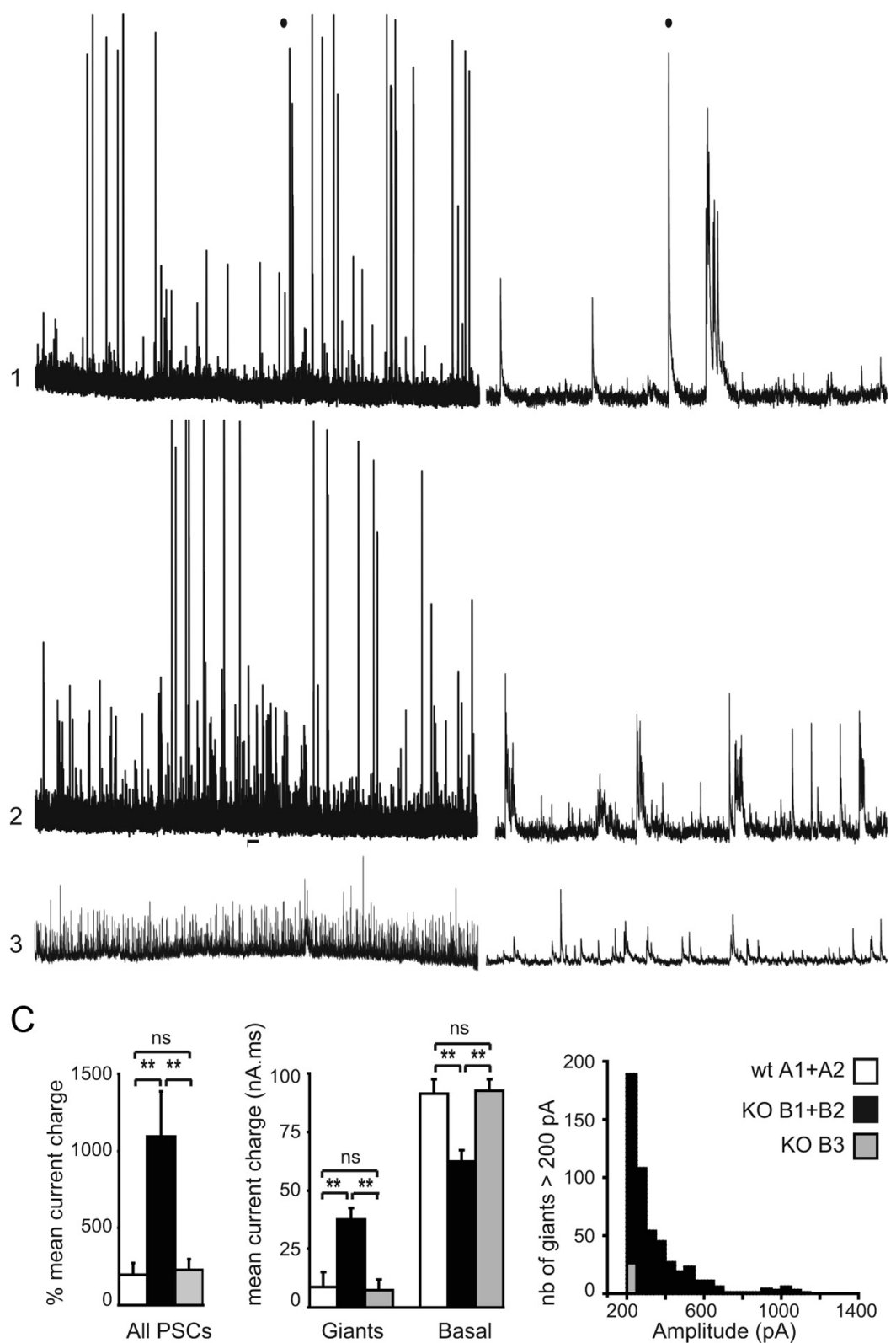

Figure 1. Spontaneous $\mathrm{GABA}_{\mathrm{A}}$ currents recorded from MSNs in basal ganglia slices from 5- to 7-month-old wt or Pink1 ${ }^{-1-}$ mice. Voltage-clamp recordings of $\mathrm{GABA}_{\mathrm{A}} \mathrm{sPSC}\left(V_{\mathrm{H}}=+10 \mathrm{mV}\right)$ at two different time scales. $A$, Tonic pattern of $\mathrm{GABA}_{\mathrm{A}} \mathrm{sPSC}$ in wt striatum in the absence (70\% of MSNs; $\boldsymbol{A}$ 1) or rare presence of single sPSCs $>200 \mathrm{pA}(\mathbf{O})(30 \%$ of MSNs; $\boldsymbol{A 2}$ ). B1, B2, 0scillatory pattern of $\mathrm{GABA}_{\mathrm{A}} \mathrm{SPSC}$ recorded in Pink1 ${ }^{-1-}$ striatum observed in $74 \%$ of MSNs and characterized by the frequent presence of giant events: single sPSCs $(\mathbf{O})$ and bursts of sPSCs $(\square)(B 1, B 2)$. B3, Tonic pattern in the remaining MSNs (26\%). The calibration of event amplitude is the same for all recordings in $\boldsymbol{A}$ and $\boldsymbol{B}$ and the scale is identical for the left and right column. $\boldsymbol{C}$ (from left to $\left(1096 \pm 289\right.$ nA.ms, $p=7.10^{-4}$ compared with $(\mathrm{A} 1+\mathrm{A} 2)$ due to the presence of numerous giant $\mathrm{GABA}_{\mathrm{A}}$ sPSCs occurring either singly or in bursts. Single giant $\mathrm{GABA}_{\mathrm{A}}$ sPSCs had a higher amplitude $(340 \pm 25$ pA; range: $200-1100 \mathrm{pA}, n=$ 532 events/17 cells; $\left.p=1 \times 10^{-4}\right)$ and a higher frequency $(0.23 \pm 0.06 \mathrm{~Hz} ; p=$ 0.03 ) than giant sPSCs from control mice (Fig. 1B1,C). When present, bursts of $\mathrm{GABA}_{\mathrm{A}}$ sPSCs recurred at intervals of $45.5 \pm 17.1 \mathrm{~s}$ during periods of $461.7 \pm$ $50.4 \mathrm{~ms}$ (Fig. 1B2) with a mean intraburst frequency of $38.5 \pm 3.8 \mathrm{~Hz}$ and a mean amplitude of $82.5 \pm 7.6 \mathrm{pA}(n=112$ events/10 cells). This new giant and oscillatory pattern was observed in $74 \%$ of the recorded Pink $1^{-1-}$ MSNs $(n=20 / 27)$. In the remaining $26 \%$ of Pink $1^{-1-}$ MSNs $(n=7 / 27), \mathrm{GABA}_{\mathrm{A}}$ sPSCs were tonic (Fig. $1 B 3)$ with a mean current charge (232 \pm $65 \mathrm{nA} . \mathrm{ms})$ and mean frequency ( $2.1 \pm 0.5$ $\mathrm{Hz}$ ) similar to those of the control tonic pattern but with a higher mean amplitude $(48.9 \pm 4.8 \mathrm{pA})(p=0.3, p=0.7, p=0.01$ respectively; nonpaired Student's $t$ test; $n=7$ ) (Fig. 1C). In conclusion, spontaneous $\mathrm{GABA}_{\mathrm{A}}$ sPSCs from Pink1 ${ }^{-1-}$ mice were strikingly large and bursty in $\sim 70 \%$ of MSNs assayed.

\section{STN lesion or chronic levodopa treatment returns the giant or oscillatory pattern of $\mathrm{GABA}_{\mathrm{A}}$ currents of Pink $1^{-l-}$ MSNs to control} STN neurons of Pink $1^{-1-}$ mice displayed the characteristic electrophysiological signature of dopamine-depletion; i.e., recurrent, spontaneous bursts of spikes as reported in rodent and primate pharmacological models of PD (Hammond et al., 2007). This is in contrast to STN neurons from 5- to 7-month-old wt mice which displayed regular tonic activity (Fig. $2 A, B)$. STN bursts of spikes in the mutant mice were generated by spontaneous bursts of EPSPs as shown by patch-clamp recordings in current-clamp mode in the continuous presence of the $\mathrm{GABA}_{\mathrm{A}}$ recep-

$\leftarrow$

right), Quantification of the data from wt MSNs as shown in $A 1+A 2$ (white) and from Pink1 ${ }^{-1-}$ MSNs as shown in $B 1+B 2$ (black) or $B 3$ (gray). The mean current charge of $G A B A_{A} S P S C$ s increased fivefold between $A 1+A 2$ and $B 1+B 2$. Giant events represented $9 \%$ and $38 \%$ of the total current charge in $A 2$ and $B 1+B 2$, respectively, and the baseline events $(\angle 200 \mathrm{pA})$ represented $91 \%$ and $62 \%$ of the total current charge in $A 1+A 2$ and $B 1+B 2$, respectively. The distribution of single giant sPSCs $>200 \mathrm{pA}$ shows the increased number of these events and the presence of very large amplitude events $(>1000 \mathrm{pA})$ in $B 1+B 2$ compared with $A 2$. Error bars indicate $S E M .{ }^{* *} p<0.01$ 


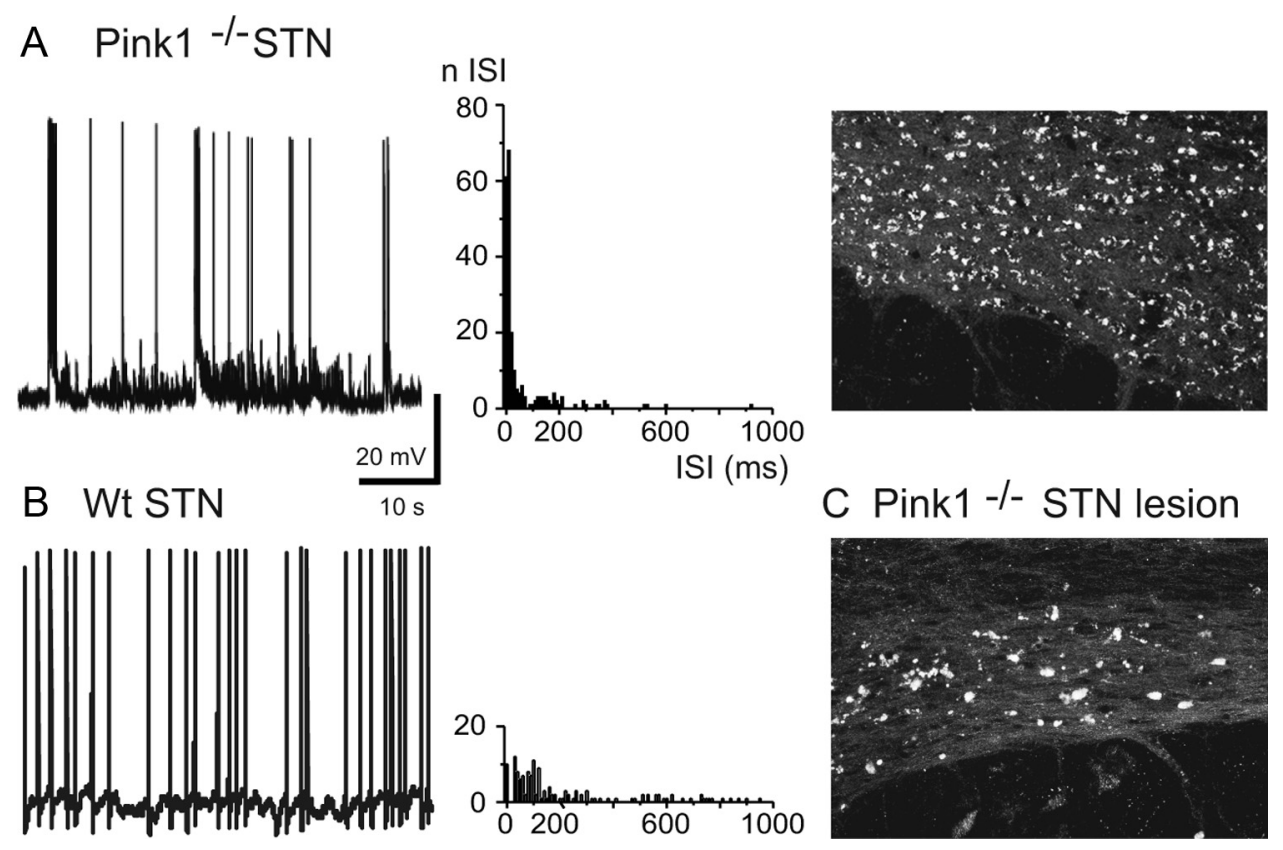

Figure 2. Characteristics of the STN and STN neurons from wt, Pink $1^{-/-}$and Pink $1^{-/-}$STN-lesioned mice. Example traces of the spontaneous bursting activity of Pink ${ }^{-/-}$STN neurons (current clamp, whole cell, $V_{\mathrm{m}}=-70 \mathrm{mV}, \boldsymbol{A}$, left) compared with the spontaneous tonic activity of wt STN neurons $\left(V_{\mathrm{m}}=-70 \mathrm{mV}\right.$, $\boldsymbol{B}$, left) and corresponding inter spike interval histograms (bin: $10 \mathrm{~ms}$ ) ( $\boldsymbol{A}, \boldsymbol{B}$, middle). Confocal images of the NeuN-positive neurons in Pink1 ${ }^{-1-}$ STN from the nonlesioned ( $\boldsymbol{A}$, right) and lesioned $(\boldsymbol{C})$ sides (stacks of $16 \mu \mathrm{m}$ thickness). The lesion was restricted to the STN region (STN + part of zona incerta) and did not extend to the thalamus.

tor antagonist, gabazine $(5 \mu \mathrm{M})$. Recorded in voltage-clamp mode $\left(V_{\mathrm{H}}=-60 \mathrm{mV}\right)$ in the presence of gabazine $(5 \mu \mathrm{M})$, the corresponding spontaneous EPSCs also displayed a bursting pattern. They were completely blocked by the application of antagonists of ionotropic glutamatergic receptors CNQX (10 $\mu \mathrm{M})$ and D-APV (40 $\mu \mathrm{M}$; data not shown) (Ammari et al., 2011).

We next tested whether kainate lesion of the dysfunctional STN would rescue the electrophysiological signature of dopamine depletion in the striatum of Pink $1^{-1-}$ mice. In 5- to 7 -month-old Pink $1^{-1-}$ mice where at least $80 \%$ of STN neurons were lost after kainic acid injection (Fig. $2 A$ right, $C$ ), without alteration of $\mathrm{mDA}$ neurons or their terminals in the striatum (data not shown), the first observation was a significant change in morphological characteristics of MSNs. Though Neurolucida reconstructed biocytin-labeled MSNs from Pink1 ${ }^{-1-}$ mice before and after STN lesion had a similar mean number of dendritic trunks $(6.0 \pm 0.3$ vs $5.0 \pm 0.5, p=0.09)$, the dendritic tree of Pink $1^{-/-}$MSNs occupied a much larger volume when the STN was intact $\left((16.2 \pm 8.6) \times 10^{6} \mu \mathrm{m}^{3}, n=22\right)$ than when it was lesioned $\left((2.5 \pm 0.3) \times 10^{6} \mu \mathrm{m}^{3}, n=14, p=0.003\right)$ (Fig. $3 A$, top). Accordingly, the mean dendritic length of the Pink $1^{-/-}$ MSNs (2970 $\pm 255 \mu \mathrm{m}, n=20)$ was significantly longer than the mean dendritic length of MSNs from Pink $1^{-1-}$ STN-lesioned mice $(2085 \pm 72 \mu \mathrm{m}, n=14 ; p=0.003)$. This effect was maximal at distances of 130 and $170 \mu \mathrm{m}$ from the soma upon comparison of Pink $1^{-1-}$ animals with STN intact $(942 \pm 64 \mu \mathrm{m}$ and $542 \pm 77$ $\mu \mathrm{m})$ versus lesioned $(600 \pm 52$ and $148 \pm 38 \mu \mathrm{m}, p=0.001$ and 0.0001 respectively). The mean number of intersections at 130 and $170 \mu \mathrm{m}$ from the soma was significantly higher in Pink $1^{-1-}$ MSNs when the STN was intact $(16.2 \pm 2.4$ and $10.7 \pm 3.6)$ than when it was lesioned $(5.7 \pm 1.2$ and $0.7 \pm 0.4)(p=0.0001$ and 0.0002 , respectively; Fig. $3 A$, bottom).

In $79 \%$ of MSNs from STN-lesioned Pink $1^{-/-}$mice we observed tonic $\mathrm{GABA}_{\mathrm{A}}$ sPSCs $(n=30 / 38)$ with characteristics similar to those recorded from wt MSNs of the same age $(p=0.13)$; i.e., with low-frequency $(3.0 \pm 0.5 \mathrm{~Hz})$ and low-amplitude $(41.7 \pm 2.2 \mathrm{pA})$ events and without giant or bursting events (Fig. $3 B 1)$. The mean total current charge ( $287 \pm 65$ nA.ms, $94 \pm 2 \%$ of the total current charge) was also similar $(p=0.1)$ to that of tonic sPSCs from Pink1 ${ }^{-/-}$MSNs (Fig. 3B3, left). Either single giant $\mathrm{GABA}_{\mathrm{A}}$ sPSCs $(n=7 / 38 \mathrm{MSNs}$; Fig. $3 \mathrm{~B} 2)$ or rare bursts $(n=1 / 38 \mathrm{MSN})$ were observed in the remaining $21 \%$ of MSNs ( $n=8 / 38$ cells). These giant $\mathrm{GABA}_{\mathrm{A}}$ sPSCs had a lower mean amplitude $(240.7 \pm 3.7 \mathrm{pA}$; range, $203-341 \mathrm{pA} ; n=84$ events $/ 7$ cells, $p=0.002$; Fig. 3 B3) but a similar frequency $(0.20 \pm 0.11 \mathrm{~Hz}$ $p=0.9)$ to Pink $1^{-1-}$ MSNs.

To test whether decreased phasic release of dopamine in the basal ganglia circuit underlies both above observations, we chronically treated Pink $1^{-1-}$ mice with levodopa (see methods) and recorded spontaneous $\mathrm{GABA}_{\mathrm{A}}$ sPSCs from MSNs. All recorded MSNs $(100 \%, n=9)$ displayed a tonic pattern of $\mathrm{GABA}_{\mathrm{A}}$ sPSCs similar to those recorded from wt MSNs of the same age i.e., without giant or bursting events (Fig. 3C1,C2). GABA ${ }_{\mathrm{A}}$ sPSCs had a frequency $(0.9 \pm 0.4 \mathrm{~Hz})$, amplitude $(47.6 \pm 7.9 \mathrm{pA})$ and mean current charge ( $59 \pm 19 \mathrm{nA} . \mathrm{ms})$ that were not significantly different from those of the tonic pattern recorded in wt $(p=0.25$, $p=0.47$ and $p=0.11$, respectively $)$ or in Pink $1^{-1-}(p=0.04$, $p=0.8$ and $p=0.02$, respectively) MSNs (Fig. 3C3).

\section{Discussion}

Our results show that Pink1 ${ }^{-/-}$mouse basal ganglia are characterized by specific electrophysiological signatures. PINK1 deficiency profoundly alters transmission through $\mathrm{GABA}_{\mathrm{A}}$ receptors in $75 \%$ of striatal MSNs, causing oscillatory currents consisting of giant sPSCs and/or bursts of sPSCs. It also shifts STN neuronal activity from single spikes to rhythmic bursts. Similar signatures were previously identified in vitro in severe dopaminergic deficiency states produced pharmacologically (Hammond et al., 2007; Dehorter et al., 2009; Ammari et al., 2011). 
A Pink1 $-/-$ MSN
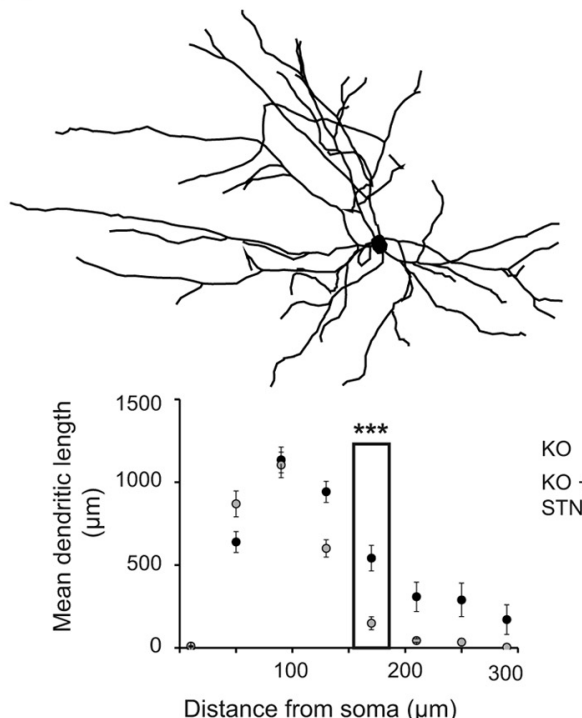

B GABA AsPSCs after STN lesion
Pink1 ${ }^{-/-}$MSN after STN lesion
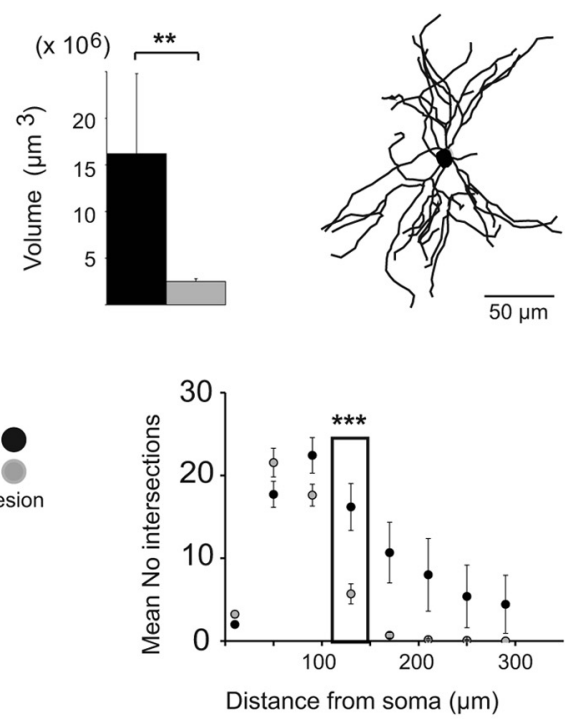

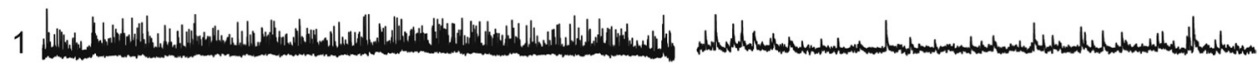

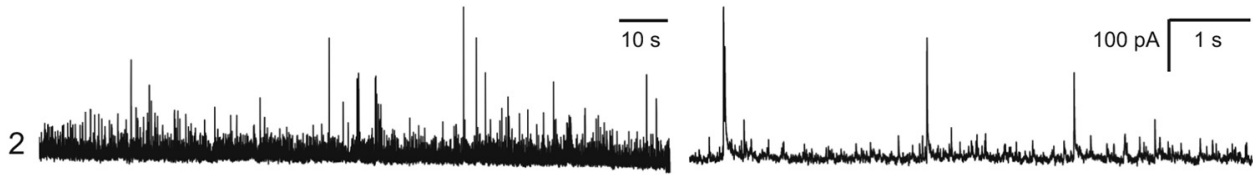

3

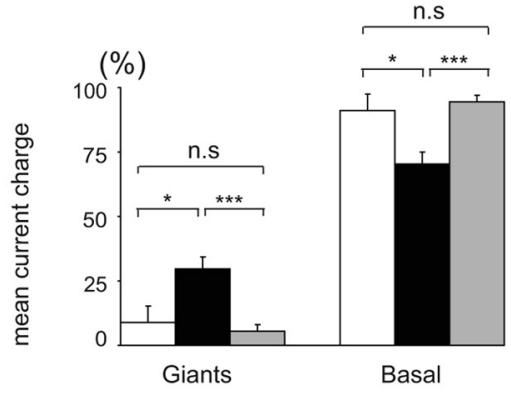

C GABA AsPSCs after levodopa treatment

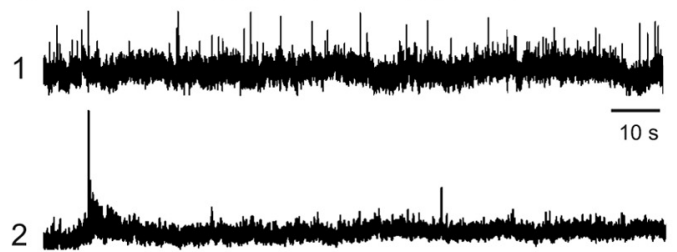

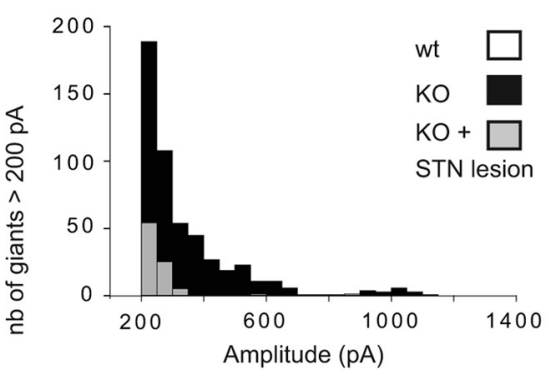

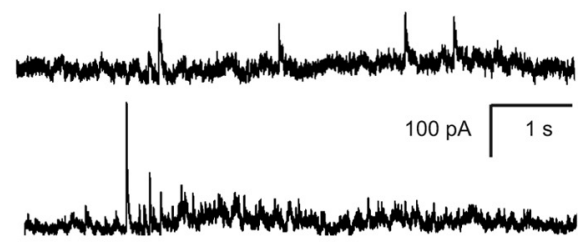

3

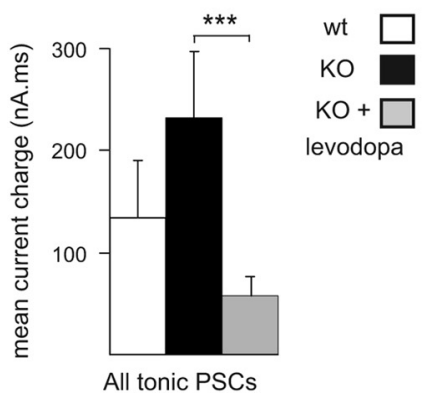

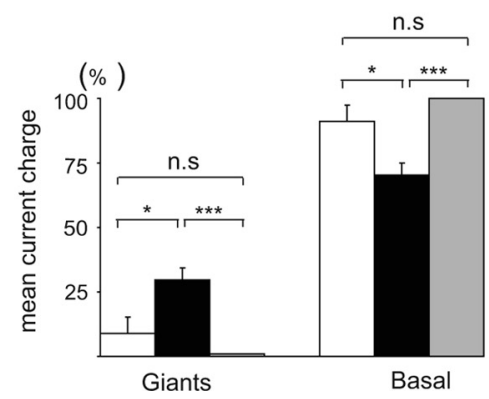
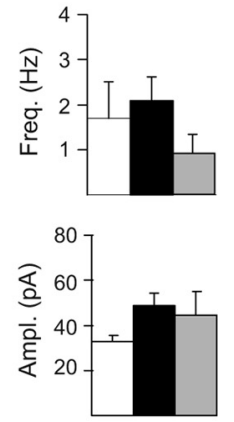

Figure 3. Spontaneous $\mathrm{GABA}_{\mathrm{A}}$ currents recorded from MSNs in basal ganglia slices from 5- to 7-month-old Pink1 ${ }^{-1-}$ mice bearing a chronic lesion of the STN or chronically treated with levodopa. $A$, Top, Neurolucida reconstruction of biocytin-filled Pink $1^{-/-}$MSNs in the absence (left) or presence (right) of an STN lesion. The histogram in the middle indicates the (Figure legend continues.) 
Our previous work using 6-hydroxydopamine (6-OHDA)treated mice as a model of dopamine depletion in late-stage $\mathrm{PD}$ showed the occurrence of giant $\mathrm{GABA}_{\mathrm{A}}$ sPSCs in MSNs, not associated with changes in the reversal potential for GABA or the resting membrane potential, or alteration of cholinergic signals. Rather, these giant sPSCs result from a change in the activity of GABAergic low-threshold spike (LTS) interneurons of the striatum. This leads to the generation of repetitive giant bursts of GABA currents in a large subpopulation of MSNs. In the STN, the dopamine-depleted state also results in a burst of spikes, but the mechanism is still a matter of controversy. We and others have suggested that dopamine depletion uncovers a polysynaptic glutamatergic network within the STN that generates bursts of EPSCs and spikes specifically when activated by cortical afferents (Shen and Johnson, 2006; Ammari et al., 2010, 2011). The role of the subthalamopallidal-pallidosubthalamic loop, which was first suggested as central (Plenz and Kital, 1999), now seems accessory (Tachibana et al., 2011).

Increased bursting activity of striatal LTS interneurons was previously observed after nearly complete dopamine depletion or mild loss of dopaminergic neurons (Janssen et al., 2012). However, the observation of similar electrophysiological signatures in 5- to 7-month-old Pink1 ${ }^{-1-}$ mice came as a surprise, as $\mathrm{mDA}$ neurons in these animals are intact, their striatal dopamine levels are only moderately reduced (20\%), and they display no significant locomotor deficit at this age (Gispert et al., 2009). Our data are supported by an independent report that Pink $1^{-/-}$mice have hyperexcitable mDA neurons with enhanced burst firing and a functional reduction in the activity of small-conductance $\mathrm{Ca}^{2+}$ activated potassium channels (Bishop et al., 2010). This early hyperexcitability may suggest that impaired dopamine signaling in the striatum and, in particular the STN (Kitada et al., 2007) is the limiting factor even more than dopamine deficiency.

It is interesting that this striatal hyperexcitability can be rescued by homolateral STN lesion (Centonze et al., 2005). The STN area is a well known target for surgical therapy in PD patients, either through lesion approaches or deep brain stimulation (Limousin et al., 1995; Okun and Vitek, 2004; Bronstein et al., 2011). Our observations suggest that the Pink $1^{-1-}$ mice are a model for not only the electrophysiological anomalies typical of early-stage $\mathrm{PD}$, they are also a useful tool to study the surgical modulation of

$\leftarrow$

(Figurelegend continued.) convex hull volume occupied by the corresponding dendritic trees. $A$, Bottom, 3D Sholl analysis of the dendritic tree of Pink $1^{-1-}$ MSNs in the absence or presence of an STN lesion. $\boldsymbol{B 1}, \boldsymbol{B 2}$, Voltage-clamp recordings of $\mathrm{GABA}_{\mathrm{A}} \mathrm{SPSCS}\left(V_{\mathrm{H}}=+10 \mathrm{mV}\right.$, two different time scales) from Pink $1^{-/-}$MSNs 1 month after STN lesion, showing a tonic pattern ( $79 \%$ of the MSNs; B1) and a tonic pattern with rare giant GABA $\mathrm{A}$ SPCS (21\% of MSNs; B2). B3 (from left to right), Quantification of the data from Pink $1^{-1-}$ MSNs from mice bearing a lesion of the STN and comparison with wt or Pink $1^{-/-}$MSNs. Giant events represented $5 \%$ of the total current charge in Pink $1^{-I-}$ MSNs after a lesion of the STN, a value similar to that recorded in wt MSNs (9\%), which was sixfold less than in Pink $1^{-1-}$ MSNs (30\%). The baseline events $(<200 \mathrm{pA})$ represented $91 \%$ and $95 \%$ of the total current charge in wt and Pink $1^{-1-}$ MSNs after STN lesion, respectively, but only $62 \%$ in Pink $1^{-I-}$ MSNs. The distribution of single giant sPSCs $>200 \mathrm{pA}$ shows the decreased number of these events in Pink $1^{-1-}$ MSNs after STN lesion compared with Pink $1^{-1-}$ MSNs in the cells displaying giant $s$ PSCS. C1, C2, Two representative examples of voltage-clamp recordings of $\mathrm{GABA}_{A} \mathrm{SPSCS}\left(V_{H}=+10 \mathrm{mV}\right.$, two different time scales) from Pink $1^{-1-}$ MSNs after chronic levodopa treatment, showing a tonic pattern in $100 \%$ of the MSNs. C3 (from left to right), Quantification of the data from Pink ${ }^{-1-}$ MSNs from mice treated with levodopa and comparison with wt or Pink $1^{-1-}$ MSNs: mean current charge of the tonic patterns, percentage of the mean current charge occupied by the giants ( $0 \%$ after levodopa treatment), percentage of the mean current charge occupied by the baseline events (basal), amplitude and frequency of the tonic events. Error bars indicate SEM. ${ }^{*} p<0.05,{ }^{* *} p<$ $0.01,{ }^{* * *} p<0.001$. ns, Not significant. impaired neural circuit function in $\mathrm{PD}$. The mechanism underlying the reversal of MSN GABA activity by chronic lesion of STN neurons is not studied here, but is likely to result from the suppression of STN bursting neurons and transmission of the bursting pattern to corticostriatal networks either directly via the subthalamo-cortical (Degos et al., 2008) and subthalamostriatal (Kita and Kitai, 1987) pathways or indirectly via thalamic neurons (Smith et al., 1998).

In view of the age-association of $\mathrm{PD}$, it will be important to investigate at what age these electrophysiological alterations appear in genetic mouse models, whether they progress over time and how they are modulated by current PD medications. In A53T- $\alpha$-synuclein overexpressing mice as a model of autosomal dominant PD variants, early deficits of striatal dopaminergic signaling were shown to progress with age and to result in pathological synaptic plasticity, which was reversible after administration of the phosphodiesterase inhibitor zaprinast (Kurz et al., 2010; Platt et al., 2012; Tozzi et al., 2012).

In conclusion, we observed oscillatory patterns of activity in Pink $1^{-1-}$ projection neurons of the dorsal striatum and the STN, which are similar to those observed in dopamine-depleted MSNs and STN neurons in pharmacological rodent models of PD. This suggests that the dopaminergic dysfunction in these two major targets of mDA neurons is more severe, at least at rest, than expected from amperometric measures in response to local striatal stimulation (Kitada et al., 2007). The presence of these electrophysiological signatures $\sim 10$ months before the onset of locomotor deficits (Gispert et al., 2009) also provides an interesting early read-out (Ben-Ari, 2008) to assess the severity of pathology in genetic mouse models of PD. Finally, the successful reversal of this pathological hyperexcitability by STN lesions establishes a path by which to investigate the benefit of $\mathrm{PD}$ therapies and their mechanism. The Pink $1^{-1-}$ mouse model of PD is thus a useful tool to study early stages of the disease process, where reversible neuronal dysfunction rather than irreversible neuron loss dominate in the brain.

\section{Notes}

Supplemental material for this article is available at http://www.inmed. univ-mrs.fr/index.php?page $=15 \&$ id $=15$. Photos of Pink1 KO mice just after the hemilateral lesion of the subthalamic nucleus. This material has not been peer reviewed.

\section{References}

Ammari R, Lopez C, Bioulac B, Garcia L, Hammond C (2010) Subthalamic nucleus evokes similar long lasting glutamatergic excitations in pallidal, entopeduncular and nigral neurons in the basal ganglia slice. Neuroscience 166:808-818. CrossRef Medline

Ammari R, Bioulac B, Garcia L, Hammond C (2011) The subthalamic nucleus becomes a generator of bursts in the dopamine-depleted state. Its high frequency stimulation dramatically weakens transmission to the globus pallidus. Front Syst Neurosci 5:43. Medline

Ben-Ari Y (2008) Neuro-archaeology: pre-symptomatic architecture and signature of neurological disorders. Trends Neurosci 31:626-636. CrossRef Medline

Benazzouz A, Piallat B, Ni ZG, Koudsie A, Pollak P, Benabid AL (2000) Implication of the subthalamic nucleus in the pathophysiology and pathogenesis of Parkinson's disease. Cell Transplant 9:215-221. Medline

Bentivoglio AR, Cortelli P, Valente EM, Ialongo T, Ferraris A, Elia A, Montagna P, Albanese A (2001) Phenotypic characterisation of autosomal recessive PARK6-linked parkinsonism in three unrelated Italian families. Mov Disord 16:999-1006. CrossRef Medline

Bergman H, Wichmann T, Karmon B, DeLong MR (1994) The primate subthalamic nucleus. II. Neuronal activity in the MPTP model of parkinsonism. J Neurophysiol 72:507-520. Medline

Beurrier C, Ben-Ari Y, Hammond C (2006) Preservation of the direct and 
indirect pathways in an in vitro preparation of the mouse basal ganglia. Neuroscience 140:77-86. CrossRef Medline

Bishop MW, Chakraborty S, Matthews GA, Dougalis A, Wood NW, Festenstein R, Ungless MA (2010) Hyperexcitable substantia nigra dopamine neurons in PINK1- and HtrA2/Omi-deficient mice. J Neurophysiol 104: 3009-3020. CrossRef Medline

Bronstein JM, Tagliati M, Alterman RL, Lozano AM, Volkmann J, Stefani A, Horak FB, Okun MS, Foote KD, Krack P, Pahwa R, Henderson JM, Hariz MI, Bakay RA, Rezai A, Marks WJ Jr, Moro E, Vitek JL, Weaver FM, Gross RE, et al. (2011) Deep brain stimulation for Parkinson disease: an expert consensus and review of key issues. Arch Neurol 68:165. CrossRef Medline

Centonze D, Gubellini P, Rossi S, Picconi B, Pisani A, Bernardi G, Calabresi P, Baunez C (2005) Subthalamic nucleus lesion reverses motor abnormalities and striatal glutamatergic overactivity in experimental parkinsonism. Neuroscience 133:831-840. CrossRef Medline

Cossart R, Hirsch JC, Cannon RC, Dinoncourt C, Wheal HV, Ben-Ari Y, Esclapez M, Bernard C (2000) Distribution of spontaneous currents along the somato-dendritic axis of rat hippocampal CA1 pyramidal neurons. Neuroscience 99:593-603. CrossRef Medline

Degos B, Deniau JM, Le Cam J, Mailly P, Maurice N (2008) Evidence for a direct subthalamo-cortical loop circuit in the rat. Eur J Neurosci 27:25992610. CrossRef Medline

Dehorter N, Guigoni C, Lopez C, Hirsch J, Eusebio A, Ben-Ari Y, Hammond C (2009) Dopamine-deprived striatal GABAergic interneurons burst and generate repetitive gigantic IPSCs in medium spiny neurons. J Neurosci 29:7776-7787. CrossRef Medline

Gasser T (2009) Molecular pathogenesis of Parkinson disease: insights from genetic studies. Expert Rev Mol Med 11:e22. CrossRef Medline

Gispert S, Ricciardi F, Kurz A, Azizov M, Hoepken HH, Becker D, Voos W, Leuner K, Müller WE, Kudin AP, Kunz WS, Zimmermann A, Roeper J, Wenzel D, Jendrach M, García-Arencíbia M, Fernández-Ruiz J, Huber L, Rohrer H, Barrera M, et al. (2009) Parkinson phenotype in aged PINK1deficient mice is accompanied by progressive mitochondrial dysfunction in absence of neurodegeneration. PLoS One 4:e5777. CrossRef Medline

Hammond C, Bergman H, Brown P (2007) Pathological synchronization in Parkinson's disease: networks, models and treatments. Trends Neurosci 30:357-364. CrossRef Medline

Janssen ML, Zwartjes DG, Tan SK, Vlamings R, Jahanshahi A, Heida T, Hoogland G, Steinbusch HW, Visser-Vandewalle V, Temel Y (2012) Mild dopaminergic lesions are accompanied by robust changes in subthalamic nucleus activity. Neurosci Lett 508:101-105. CrossRef Medline

Kessler KR, Hamscho N, Morales B, Menzel C, Barrero F, Vives F, Gispert S, Auburger G (2005) Dopaminergic function in a family with the PARK6 form of autosomal recessive Parkinson's syndrome. J Neural Transm 112: 1345-1353. CrossRef Medline

Kita H, Kitai ST (1987) Efferent projections of the subthalamic nucleus in the rat: light and electron microscopic analysis with the PHA-L method. J Comp Neurol 260:435-452. CrossRef Medline

Kitada T, Pisani A, Porter DR, Yamaguchi H, Tscherter A, Martella G, Bonsi
P, Zhang C, Pothos EN, Shen J (2007) Impaired dopamine release and synaptic plasticity in the striatum of PINK1-deficient mice. Proc Natl Acad Sci U S A 104:11441-11446. CrossRef Medline

Klinkenberg M, Gispert S, Dominguez-Bautista JA, Braun I, Auburger G, Jendrach M (2012) Restriction of trophic factors and nutrients induces PARKIN expression. Neurogenetics 13:9-21. CrossRef Medline

Kurz A, Double KL, Lastres-Becker I, Tozzi A, Tantucci M, Bockhart V, Bonin M, García-Arencibia M, Nuber S, Schlaudraff F, Liss B, Fernández-Ruiz J, Gerlach M, Wüllner U, Lüddens H, Calabresi P, Auburger G, Gispert S (2010) A53T-alpha-synuclein overexpression impairs dopamine signaling and striatal synaptic plasticity in old mice. PLoS One 5:e11464. CrossRef Medline

Limousin P, Pollak P, Benazzouz A, Hoffmann D, Le Bas JF, Broussolle E, Perret JE, Benabid AL (1995) Effect of parkinsonian signs and symptoms of bilateral subthalamic nucleus stimulation. Lancet 345:91-95. CrossRef Medline

Mei Y, Zhang Y, Yamamoto K, Xie W, Mak TW, You H (2009) FOXO3adependent regulation of Pink1 (Park6) mediates survival signaling in response to cytokine deprivation. Proc Natl Acad Sci U S A 106:5153-5158. CrossRef Medline

Okun MS, Vitek JL (2004) Lesion therapy for Parkinson's disease and other movement disorders: update and controversies. Mov Disord 19:375-389. CrossRef Medline

Platt NJ, Gispert S, Auburger G, Cragg SJ (2012) Striatal dopamine transmission is subtly modified in human A53Talpha-synuclein overexpressing mice. PLoS One 7:e36397. CrossRef Medline

Plenz D, Kital ST (1999) A basal ganglia pacemaker formed by the subthalamic nucleus and external globus pallidus. Nature 400:677-682. CrossRef Medline

Pyapali GK, Sik A, Penttonen M, Buzsaki G, Turner DA (1998) Dendritic properties of hippocampal CA1 pyramidal neurons in the rat: intracellular staining in vivo and in vitro. J Comp Neurol 391:335-352. CrossRef Medline

Shen KZ, Johnson SW (2006) Subthalamic stimulation evokes complex EPSCs in the rat substantia nigra pars reticulata in vitro. J Physiol 573:697-709. CrossRef Medline

Smith Y, Bevan MD, Shink E, Bolam JP (1998) Microcircuitry of the direct and indirect pathways of the basal ganglia. Neuroscience 86:353-387. CrossRef Medline

Tachibana Y, Iwamuro H, Kita H, Takada M, Nambu A (2011) Subthalamopallidal interactions underlying parkinsonian neuronal oscillations in the primate basal ganglia. Eur J Neurosci 34:1470-1484. CrossRef Medline

Tozzi A, Costa C, Siliquini S, Tantucci M, Picconi B, Kurz A, Gispert S, Auburger G, Calabresi P (2012) Mechanisms underlying altered striatal synaptic plasticity in old A53T-alpha synuclein overexpressing mice. Neurobiol Aging 33:1792-1799. CrossRef Medline

Zhou C, Huang Y, Przedborski S (2008) Oxidative stress in Parkinson's disease: a mechanism of pathogenic and therapeutic significance. Ann N Y Acad Sci 1147:93-104. CrossRef Medline 